\title{
Multivariate assessment of subjective and objective measures of social and family satisfaction in Veterans with history of traumatic brain injury
}

\author{
Henry J. Orff, PhD; ${ }^{*}$ Chelsea C. Hays, BS; ${ }^{2}$ Elizabeth W. Twamley, PhD $^{1}$ \\ ${ }^{1}$ Veterans Integrated Service Network 22 Center of Excellence for Stress and Mental Health, Clinical and Health Ser- \\ vices Research, Department of Veterans Affairs San Diego Healthcare System, San Diego, CA; and Department of Psy- \\ chiatry, University of California San Diego, San Diego, CA; ${ }^{2}$ San Diego State University/University of California San \\ Diego Joint Doctoral Program in Clinical Psychology, San Diego, CA
}

\begin{abstract}
Approximately 20\% of current-era Veterans have sustained a traumatic brain injury (TBI), which can result in persistent postconcussive symptoms. These symptoms may disrupt family and social functioning. We explored psychiatric, postconcussive, and cognitive factors as correlates of objective functioning and subjective satisfaction in family and social relationships. At entry into a supported employment study, 50 unemployed Veterans with a history of mild to moderate TBI and current cognitive impairment were administered baseline assessments. Multivariate stepwise regressions determined that higher levels of depressive symptomatology were strongly associated with less frequent social contact, as well as lower subjective satisfaction with family and social relationships. Worse verbal fluency predicted less frequent social contact, whereas worse processing speed and switching predicted higher levels of subjective satisfaction with family relationships. The pattern of results remained similar when examining those Veterans with only mild TBI. Depressive symptoms and cognitive functioning may affect Veterans' social contact and satisfaction with family and social relationships. Evidencebased interventions addressing depression and cognition may therefore aid in improving community reintegration and satisfaction with social and family relationships.
\end{abstract}

Key words: cognitive performance, community reintegration, depression, family contacts, postconcussive symptoms, quality of life, social relationships, social satisfaction, traumatic brain injury, Veterans.

\section{INTRODUCTION}

The Centers for Disease Control and Prevention indicate that an estimated 1.7 million cases of traumatic brain injury (TBI) are reported yearly in the United States [1]. A history of TBI is even more common among servicemembers deployed in support of Operation Iraqi Freedom/Operation Enduring Freedom (OIF/OEF), where approximately 20 percent have reportedly sustained a TBI [2]. In fact, TBI is considered the signature wound among Veterans of OIF/OEF, with increased rates of TBI in this population being attributed to the blast injuries caused by close proximity to artillery, mortar, rocket

\footnotetext{
Abbreviations: CAPS = Clinician-Administered PTSD Scale, CVLT-II = California Verbal Learning Test-Second Edition, DKEFS = Delis-Kaplan Executive Function System, HAM-D = Hamilton Depression Rating Scale, LOC = loss of consciousness, NSI = Neurobehavioral Symptom Inventory, OIF/OEF = Operation Iraqi Freedom/Operation Enduring Freedom, PTSD = posttraumatic stress disorder, QOL = quality of life, QOLI-BV = Quality of Life Interview-Brief Version, TBI = traumatic brain injury, VA = Department of Veterans Affairs, WAIS-III = Wechsler Adult Intelligence Scale-Third Edition.

*Address all correspondence to Henry J. Orff, PhD; VA San Diego Healthcare System, 3350 La Jolla Village Dr (9151B), San Diego, CA 92161; 858-642-6492; fax: 858-6426340. Email: horff@ucsd.edu

http://dx.doi.org/10.1682/JRRD.2014.11.0295
} 
shells, mines, bombs, grenades, and improvised explosive devices [3-4]. Although there is variability in diagnostic criteria, the vast majority of military TBIs are classified as mild to moderate, according to the definition used by the Department of Veterans Affairs (VA) and Department of Defense [3].

Although most combat Veterans are able to make a successful transition back into civilian life, mental health problems and functioning difficulties make the reintegration process more difficult [5]. Family and social relationships are important components to successful reintegration [6-7] and are known to be affected by mental health and functional problems [6-7]. Therefore, it is important to explore reintegration in the context of TBI because it may be of particular concern in this population [8].

Those who sustain a TBI in the mild to moderate range often experience postconcussive symptoms such as sleep disturbance, fatigue, headache pain, irritability, mood disturbances, and cognitive symptoms [9-11]. Cognitive symptoms in this group tend to be related to concentration, attention, processing speed, learning, memory, prospective memory, and executive functioning [10,1216]. Although most individuals with mild to moderate TBI histories recover from these postconcussive symptoms within days to weeks [17-18], as many as 10 to 20 percent suffer from persistent postconcussive symptoms that do not resolve within this time frame [19]. These symptoms can hamper the successful reintegration of Veterans with a history of TBI by limiting the functional recovery required for community reintegration [20-21].

Those with a history of TBI are also more likely to be diagnosed with a psychiatric disorder, with posttraumatic stress disorder (PTSD) and depression being the most prevalent $[2,10,22]$. Within the returning Veteran population, it is estimated that 73 percent of Veterans with a TBI are also diagnosed with PTSD and 47 percent with depression [23]. Other common psychiatric comorbidities include substance abuse, adjustment disorders, and other anxiety disorders [24]. When looking closely at the relationship between psychiatric symptoms and TBI, it appears that these psychiatric symptoms are more attributable to psychosocial functioning, subjective health, and postconcussive symptom severity than to the characteristics of the TBI itself [22,25-26]. These psychiatric comorbidities are especially concerning in the context of TBI recovery because they can impede successful community reintegration [5].

The high prevalence of TBI in military and Veteran populations has prompted research focusing on long-term patient outcomes, such as quality of life (QOL), which can be measured with objective ratings of activity participation as well as subjective ratings of life satisfaction. Individuals who have sustained a TBI tend to report worse QOL than those who have not sustained a TBI [27], even those who have sustained injuries in the mild to moderate range [28-29]. In the context of mild TBI, it appears that higher rates of postconcussive symptoms are also associated with worse QOL [30]. The strongest correlates of subjective QOL in a recent study of Veterans were depressive symptoms, fatigue, and sleep difficulty [29]. Little is known about correlates of objective QOL, especially in the domain of social and community reintegration. However, studies have found that cognitive impairments and depression are associated with decreased social contact and greater loneliness [31-32] and that higher levels of loneliness are associated with lower levels of social integration and perceived social support [33].

Given that TBI is associated with postconcussive and psychiatric symptoms that can hinder community reintegration and that family and social relationships are both important in the successful reintegration of Veterans [67], it is important to know the factors associated with family and social functioning post-TBI. Given the high prevalence of psychiatric comorbidities, postconcussive symptoms, and cognitive impairments following TBI and their relationship to functional recovery from TBI, we hypothesized that psychiatric and postconcussive symptom severity, as well as cognitive functioning, would be associated with objective frequency of family and social contact and subjective satisfaction with family and social relationships.

\section{METHODS}

\section{Subjects}

Data were acquired from baseline assessments of 50 Veterans receiving healthcare at the VA San Diego Healthcare System and enrolled in a research study examining the effect of Cognitive Symptom Management and Rehabilitation Therapy within a supported employment program [34-35] for unemployed Veterans. Inclusion criteria for the larger study were (1) OIF/OEF Veteran status; (2) history of mild to moderate TBI defined as a loss of consciousness (LOC) for less than $24 \mathrm{~h}$ and posttraumatic amnesia for less than $7 \mathrm{~d}$ according to the clinical practice guideline [36], documented in a prior clinical neuropsychological evaluation and confirmed by a structured interview; (3) neuropsychological impairment in at least one 
cognitive domain, as documented in a prior valid clinical neuropsychological assessment; and (4) current unemployment but seeking work. Veterans who met criteria for current alcohol and/or substance abuse or dependence or who were participating in other intervention studies were excluded. Participants with complete baseline data were on average $31.8 \pm 7.3 \mathrm{yr}$ old and had completed $13.4 \pm 1.6 \mathrm{yr}$ of education; 96 percent were men, and 40 percent were members of a racial or ethnic minority group. The median length of LOC for the worst TBI was $1.3 \mathrm{~min}$, and the median length of total LOCs summed across TBIs (up to a maximum of 4 LOCs) was 2 min (see Table 1). Overall, 84 percent of TBIs were rated as mild and 16 percent were moderate.

\section{Measures}

In an effort to fully explore the factors affecting social and family functioning and satisfaction in this Veteran patient population, we examined several measures of QOL and psychiatric and cognitive functioning. The primary measures included-

1. Quality of Life Interview-Brief Version (QOLI-BV) [37]. The QOLI-BV is a structured interview assessing objective and subjective quality of life in eight domains (living situation, daily activities and functioning, family relationships, social relationships, finances, work and school, legal and safety issues, and health),

Table 1.

Sample demographics. Data presented as mean \pm standard deviation unless otherwise noted. $(N=50)$.

\begin{tabular}{lc}
\hline \multicolumn{1}{c}{ Demographic } & Value \\
\hline Age (yr) & $31.8 \pm 7.3$ \\
Education (yr) & $13.4 \pm 1.6$ \\
Sex: Male (\%) & 96.0 \\
Race: Caucasian (\%) & 60.0 \\
Ethnicity: Hispanic/Latino (\%) & 36.0 \\
TBI Severity (\%) & \\
$\quad$ Mild & 84.0 \\
$\quad$ Moderate & 16.0 \\
LOC Length: Worst TBI (min), median (range) & $1.3(0-1440)$ \\
Total LOC Length: Across $\leq 4$ TBI (min) median range) & $2.0(0-1440)$ \\
Time Since Worst TBI (yr) & $5.3 \pm 4.1$ \\
Time Since Most Recent TBI (yr) & $4.6 \pm 3.8$ \\
Neurobehavioral Symptom Inventory & $40.8 \pm 15.0$ \\
Clinical-Administered PTSD Scale & $62.2 \pm 26.4$ \\
Hamilton Rating Scale for Depression & $20.9 \pm 9.4$ \\
Premorbid IQ Estimate, WRAT-3 Reading Scaled Score & $97.3 \pm 9.5$ \\
\hline IQ = intelligence quotient, LOC = loss of consciousness, PTSD = posttraumatic \\
stress disorder, TBI = traumatic brain injury, WRAT-3 = Wide Range Achieve- \\
ment Test 3. \\
\hline \hline
\end{tabular}

two of which (family relationships and social relationships) were the focus of our study. The domains are organized such that information is first obtained about objective functioning (e.g., "In the past year, how often did you get together with a member of your family - at least once a day, at least once a week, at least once a month, less than once a month but at least once during the year, or not at all?"). Questions regarding level of life satisfaction in that domain then follow and are rated using a Likert scale ranging from 1 (terrible) to 7 (delighted) (e.g., "How do you feel about the way things are in general between you and your family?”).

2. Hamilton Depression Rating Scale (HAM-D) [38]. The HAM-D is a 28-item measure designed to assess global depressive symptomatology and probes symptoms such as depressed mood, guilty feelings, suicide, sleep disturbances, anxiety levels, and weight loss. Scoring is based on a scale ranging from 0 (not present) to 4 (extreme symptoms) as determined by clinician interview with the patient. A subset of items from this measure (17-item version) was also used to evaluate the effect of clinical cutoff scores on primary outcome measures.

3. Clinician-Administered PTSD Scale (CAPS) [39]. The CAPS is a 30-item, clinician-administered, structured interview that can be used to determine PTSD diagnosis and measure symptom severity. The CAPS addresses issues such as onset and duration of symptoms, subjective distress, effect of symptoms on social and occupational functioning, and overall PTSD severity, with ratings made on a scale ranging from 0 (absent) to 4 (incapacitating). Note that we also used the self-report of total sleep time (obtained from item 13 on the CAPS) to examine the potential effect of sleep disturbance on family and social satisfaction.

4. Neurobehavioral Symptom Inventory (NSI) [40]. The NSI is a 22-item self-report measure that assesses severity of cognitive, physical, and emotional postconcussive symptoms over the prior 2 wk on a scale ranging from 0 (none) to 4 (very severe).

In an effort to explore the potential effect of cognitive functioning on social satisfaction, we examined tests representing several neuropsychological domains. Higher scores indicate better performance on all measures. These measures included-

1. Trials 1-5, Total and Long Delay Free Recall, from the California Verbal Learning Test-Second Edition 
(CVLT-II) [41] were used as measures of verbal list learning and memory ( $T$ score).

2. Digit Span from the Wechsler Adult Intelligence Scale-Third Edition (WAIS-III) [42] was used to assess attention and working memory (scaled score).

3. Digit Symbol from the WAIS-III was used to assess processing speed (scaled score).

4. Category Fluency from the Delis-Kaplan Executive Function System (D-KEFS) [43], which involves both processing speed and executive functioning, was used to assess speeded verbal-idea generation (scaled score).

5. Trail 4 (Letter-Number Switching) from the D-KEFS was used as a test of switching, a key aspect of executive functioning capturing cognitive flexibility (scaled score).

\section{Analyses}

Bivariate correlations were performed to examine the associations among total scores on the HAM-D, NSI, and CAPS; standard scores for the neuropsychological variables; total sleep time; and objective and subjective measures of family and social contact. We then included variables with correlations at the $p<0.10$ significance level in multivariate stepwise regressions to determine the best predictors of variance in objective and subjective family and social contact. These multivariate analyses were run twice, once using the full data set (combined mild and moderate TBI) and once for Veterans with mild TBI only. Lastly, HAM-D (17-item) and CAPS total scores were divided by established clinical cutoff scores and assessed using univariate analyses of variance to determine whether clinical diagnosis affected subjective and objective outcome measures.

\section{RESULTS}

No significant associations were found between any of the assessment measures and objective measures of family contact. For objective measures of social contact, higher levels of depressive symptomatology (HAM-D; $r=$ $-0.32 ; p=0.02$ ) were associated with less frequent social contact. Additionally, worse sleep (total sleep time from the CAPS; $r=0.29 ; p=0.04$ ) and worse performance on the Category Fluency task (D-KEFS; $r=0.35 ; p=0.01$ ) were associated with less frequent social contact, a trend that was also noted for measures of learning and memory (CVLT-II; Trials 1-5, Total and Long Delay Free Recall; both $r=0.26 ; p=0.07$. Regarding subjective satisfaction, higher levels of depressive (HAM-D) and PTSD (CAPS) symptoms were associated with lower subjective satisfaction with family relationships, as was better performance on the D-KEFS Trails 4 ( $r=-0.36$ to $-0.47 ; p<0.01$ ). A similar trend was observed for worse postconcussive symptoms (NSI) and better performance on Digit Symbol (WAIS-III) ( $r=-0.24$ to $-0.25 ; p<0.09$ ). For subjective measures of satisfaction with social relationships, only higher levels of depressive symptomatology (HAM-D) were associated with lower subjective satisfaction $(r=$ $-0.47 ; p=0.001$ ), though trends were also observed for higher levels of postconcussive symptoms (NSI; $r=$ $-0.27 ; p=0.06$ ) and better performance on the Category Fluency task ( $r=0.25 ; p=0.08$ ). (See Table 2 for complete listings of correlations.)

Table 3 presents the multivariate models of objective social contact and subjective satisfaction with family and social relationships. We found that worse depressive symptomatology and worse performance on the Category Fluency task were associated with lower levels of social contact, explaining 20 percent of the variance in the model. In the model of subjective satisfaction with family contact, worse depressive symptomatology and better performance on Digit Symbol and Trails 4 were associated with lower subjective satisfaction with family contact, accounting for 39 percent of the variance in the model. In the model examining subjective satisfaction with social relationships, worse depressive symptomatology was the only variable that explained lower levels of subjective satisfaction with social relationships, accounting for 22 percent of the variance. When we removed Veterans with moderate TBI from the models $(n=8)$, depressive symptomatology remained significantly associated with both subjective family contact and social relations, and Trail 4 remained significantly associated with subjective family contact. However, none of the variables associated with objective social contact retained significance. As well, the Digit Symbol score was no longer significantly associated with subjective family contact.

Lastly, we compared Veterans who exceeded the clinical cutoff for depressive symptomatology on the 17-item HAM-D (HAM-D $\geq 8$ ) [38] and PTSD symptomatology on the CAPS (CAPS > 65) [44] to see whether exceeding the clinical threshold on either of these measures was related to objective social contact and subjective satisfaction with family and social relationships. Compared with those scoring below the clinical cutoff on the HAM-D ( $n=$ 5), participants with significant depressive symptoms ( $n=$ 
Table 2.

Bivariate correlations between psychiatric, postconcussive, and cognitive functioning and subjective and objective measures of family and social relations. $(N=50)$.

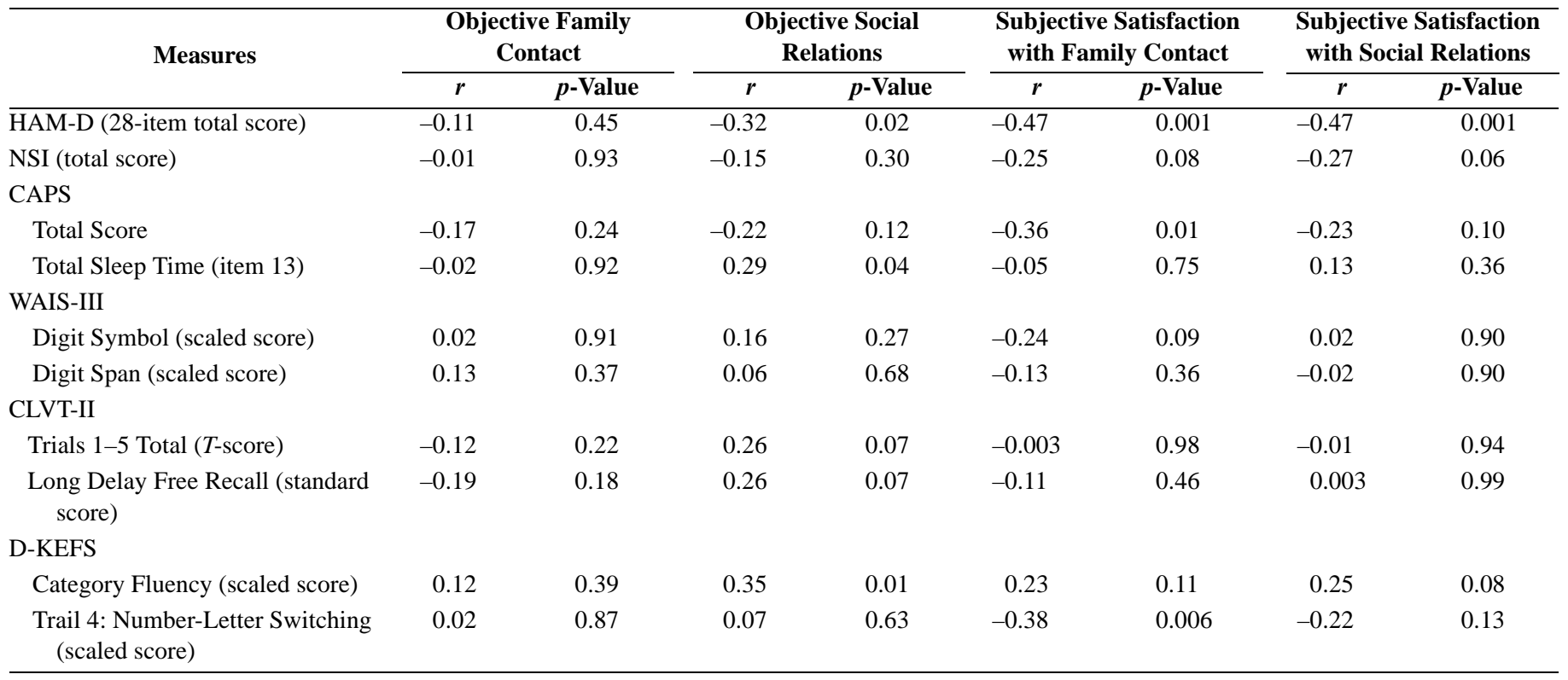

CAPS = Clinician-Administered Posttraumatic Stress Disorder Scale, CLVT-II = California Verbal Learning-Second Edition, D-KEFS = Delis-Kaplan Executive Function System, HAM-D = Hamilton Depression Rating Scale, NSI = Neurobehavioral Symptom Inventory, WAIS-III = Wechsler Adult Intelligence Scale-Third Edition.

45) had significantly lower ratings of subjective family contact $(F(1 / 48)=6.47 ; p=0.01)$ and subjective social relations $(F(1,48)=7.47 ; p=0.01)$. The groups did not differ in their reports of objective social contact $(F(1,48)=$ $1.43 ; p=0.24)$ or objective family contact $(F(1,48)=0.03$; $p=0.85)$. Compared to those scoring below the clinical cutoff on the CAPS $(n=29)$, participants with significant PTSD symptoms $(n=21)$ had significantly lower ratings of objective family contact $(F(1,48)=6.53 ; p=0.01)$, objective social contact $(F(1,48)=4.26 ; p=0.05)$, and subjective family contact $(F(1,48)=6.62 ; p=0.01)$. The groups did not differ in their reports of subjective social relations $(F(1,48)=1.98 ; p=0.17)$.

\section{DISCUSSION}

In our sample of Veterans with history of mild to moderate TBI, we found that depressive symptom severity was significantly associated with both objective and subjective measures of social functioning, with higher depressive symptom severity being associated with less frequent social contact and lower satisfaction with both family and social relationships. When those Veterans with moderate TBI were removed from our analyses, the relationship between depressive symptomatology and subjective family contact and social relations remained significant, though the relationship with objective social contact failed to retain significance. Our results with regard to cognitive performance were mixed. For the entire sample, we found that worse verbal fluency was associated with less frequent social contact, but also that slower processing speed and worse executive functioning (as measured by a switching task) were associated with higher satisfaction with family relationships. When examining just those Veterans with mild TBI, only the relationship between worse executive functioning and better perceived family contact remained significant. We found that, compared with those without significant depressive symptoms, participants with clinically significant levels of depressive symptoms reported lower levels of satisfaction with family and social contact but did not differ with regard to objective social or family contact. Conversely, Veterans with clinically relevant PTSD symptoms showed significantly lower levels of objective and subjective family contact and objective social relations but did not differ with regard to subjective social relations. 
JRRD, Volume 53, Number 5, 2016

Table 3.

Multivariate predictors of variance in objective social contact and subjective family contact and social relations.

\begin{tabular}{|c|c|c|c|}
\hline & $\boldsymbol{\beta}$ & $t$ & $p$ \\
\hline \multicolumn{4}{|l|}{ Objective Social Contact $^{*}$} \\
\hline Verbal Fluency & 0.31 & 2.26 & 0.03 \\
\hline HAM-D (Total Score) & -0.28 & -2.06 & 0.05 \\
\hline CVLT II: Long Delay Free Recall (Standard Score) & 0.22 & 1.72 & 0.09 \\
\hline CVLT II: Trials 1-5 (Total T-Score) & 0.20 & 1.51 & 0.14 \\
\hline Total Sleep Time (Score from CAPS Item 13) & 0.20 & 1.48 & 0.15 \\
\hline HAM-D (Total Score) & -0.48 & -4.01 & $<0.001$ \\
\hline Digit Symbol (Scaled Score) & -0.28 & -2.32 & 0.03 \\
\hline Trails 4 (Letter-Number Switching) & -0.25 & -2.08 & 0.04 \\
\hline CAPS (Total Score) & -0.07 & -0.46 & 0.65 \\
\hline NSI (Total Score) & 0.06 & 0.38 & 0.70 \\
\hline \multicolumn{4}{|c|}{$\begin{array}{l}{ }^{{ }^{\top} R^{2}}=0.197 \\
{ }^{\dagger} R^{2}=0.389 . \\
{ }^{\ddagger} R^{2}=0.223 . \\
\text { CAPS = Clinician-Administered PTSD Scale, CVLT-II = California Verbal Learning Test-Second Edition, HAM-D = Hamilton Depression Rating Scale, NSI = } \\
\text { Neurobehavioral Symptoms Inventory. }\end{array}$} \\
\hline
\end{tabular}

The relationship between depression and both social and family relationships found in this study is in line with our hypothesis and with previous research suggesting that comorbid psychiatric illness is a strong predictor of psychosocial functioning after TBI [25-26]. Although the literature also suggests a significant contribution of PTSD to psychosocial functioning, once we controlled for depressive symptoms, PTSD symptom severity no longer accounted for significant variance in any measure of family/social functioning or satisfaction. Our finding that worse verbal fluency was associated with less social contact in those who have experienced a TBI is consistent with our hypothesis and is a novel finding. We are not aware of any other studies investigating this relationship, but it is in line with recent research in aging showing that better cognitive performance is associated with less loneliness and more social support in the elderly [45]. It may be the case that individuals with worse verbal fluency are more isolated because of either reluctance to engage with others or rejection by social contacts. We also found significant relationships between cognitive performance and satisfaction with family relationships, although the direction of this relationship was unexpected. We hypothesized that worse cognitive perfor- mance would be associated with lower family satisfaction, but it was instead associated with higher satisfaction with family relationships. It may be the case that family members are more supportive when individuals with a history of TBI show cognitive impairments, such as slow processing speed or executive dysfunction. The differences in correlates of social and family contact, as well as subjective satisfaction, suggest that family and social contact should be measured as separate constructs and that objective measures of community reintegration (frequency of family and social contact) should be measured separately from subjective measures of satisfaction with such contact.

Ancillary analyses of the data set provided results that may help explain these findings and/or may provide avenues for future investigation. For example, when only those Veterans with mild TBI were examined, subjective reports of family and social functioning appeared to retain a stronger relationship to mood symptoms and cognitive functioning than did objective measures of social functioning. As well, when clinical cutoffs were used to compare Veterans on measures of depression and PTSD, it appeared that those Veterans with clinically significant depressive symptomatology were more likely to endorse subjective 
deficits in social functioning, whereas those with clinically significant levels of PTSD symptomatology endorsed more objective impairment in social functioning.

Our results add to the literature regarding psychiatric and neurocognitive correlates of social and family reintegration and satisfaction in Veterans with a history of TBI. In clinical settings, it is common for Veterans to report difficulty relating to friends and family members following a TBI, which can cause significant stress and life dissatisfaction. Understanding the psychiatric and neurocognitive factors that are most associated with social reintegration extends our understanding of TBI and psychiatric comorbidities and our understanding of how TBI and psychiatric comorbidities affect Veterans' functioning.

Some limitations of our study include our small sample size, as well as our inclusion of participants with only mild to moderate TBI. Another limitation of this study is that our sample was composed of only unemployed Veterans with cognitive impairment, many of whom had comorbid psychiatric symptoms. Our results may not generalize to those with severe TBI histories, those who are working, and/or those who do not have cognitive limitations. Therefore, these findings should be considered preliminary until replicated in a larger sample. The Veterans in our sample, however, by virtue of their unemployment, may be considered to be at high risk of poor community reintegration; therefore, examining community reintegration patterns and correlates in this sample may shed light on risk factors for worse social and community functioning. Future research should examine these relationships longitudinally using a larger sample and including those with histories of civilian TBI. It will also be important to examine predictors of social/family functioning and satisfaction in the context of more severe TBI given that cognitive deficits tend to be greater and community integration outcomes tend to be worse in those with more severe injuries [46-48].

Some strengths of our study include our use of objective measures of social/family functioning in conjunction with subjective measures of satisfaction, as well as our focus on a Veteran sample for whom social satisfaction and community reintegration may be problematic [49-50]. Furthermore, this study is one of the first to examine global mental health (e.g., mood, PTSD, and postconcussive symptoms) and specific areas of neurocognitive functioning that may be associated with measures of social satisfaction and reintegration.

\section{CONCLUSIONS}

Reintegration of Veterans into civilian life is a complex process that may depend on multiple factors. Given the sparse research on this important issue, we explored one component of reintegration, social and family functioning, in an attempt to determine which clinical and neuropsychological variables might have the greatest effect. Overall, our results have important clinical implications and further illustrate the effect of psychiatric comorbidities (especially depression) on social and family reintegration in Veterans with a history of TBI. Evidence-based treatment of both depression and cognitive dysfunction may therefore improve community reintegration as well as subjective satisfaction with social and family relationships.

\section{ACKNOWLEDGMENTS}

\section{Author Contributions:}

Study concept and design: H. J. Orff.

Concept and design of parent study: E. W. Twamley.

Analysis and interpretation of data: H. J. Orff.

Drafting of manuscript: H. J. Orff, C. C. Hays.

Critical revision of manuscript for important intellectual content:

E. W. Twamley.

Funding support for parent investigation: E. W. Twamley. Administrative and technical support: C. C. Hays.

Financial Disclosures: The authors have declared that no competing interests exist.

Funding/Support: This material was unfunded at the time of manuscript preparation.

Institutional Review: This study was approved by the University of California, San Diego Institutional Review Board and VA San Diego Healthcare System Research and Development Committee.

Participant Follow-Up: The authors do not plan to inform the participants of the publication of this study.

\section{REFERENCES}

1. Faul M, Xu L, Wald M, Coronado V. Traumatic brain injury in the United States: emergency department visits, Hospitalizations, and deaths. Atlanta (GA): Centers for Disease Control and Prevention; 2010.

2. Tanielian T, Haycox LH, Schell TL, Marshall GN, Burnam MA, Eibner C, Karney BR, Meredith LS, Ringel JS, Vaiana ME. Invisible wounds of war. Summary and recommendations for addressing psychological and cognitive injuries. Santa Monica (CA): Rand Corporation: 2008. 
3. Fischer H. United States military casualty statistics: Operation Iraqi Freedom and Operation Enduring Freedom. Washington (DC): Congressional Research Service, Library of Congress; 2009.

4. Gondusky JS, Reiter MP. Protecting military convoys in Iraq: An examination of battle injuries sustained by a mechanized battalion during Operation Iraqi Freedom II. Mil Med. 2005;170(6):546-49. [PMID:16001610] http://dx.doi.org/10.7205/MILMED.170.6.546

5. Sayer NA, Carlson KF, Frazier PA. Reintegration challenges in U.S. Service Members and Veterans following combat deployment. Soc Issues Policy Rev. 2014;8(1):3373. http://dx.doi.org/10.1111/sipr.12001

6. Fritz HA, Lysack C, Luborsky MR, Messinger SD. Longterm community reintegration: Concepts, outcomes and dilemmas in the case of a military service member with a spinal cord injury. Disabil Rehabil. 2015;37(16):1501-7. [PMID:25270306]

7. Wilcox SL, Oh H, Redmond SA, Chicas J, Hassan AM, Lee PJ, Ell K. A scope of the problem: Post-deployment reintegration challenges in a National Guard Unit. Work. 2015;50(1):73-83.

8. Daggett VS, Bakas T, Buelow J, Habermann B, Murray LL. Needs and concerns of male combat Veterans with mild traumatic brain injury. J Rehabil Res Dev. 2013; 50(3):327-40. [PMID:23881759]

http://dx.doi.org/10.1682/JRRD.2011.09.0168

9. Haboubi NH, Long J, Koshy M, Ward AB. Short-term sequelae of minor head injury (6 years experience of minor head injury clinic). Disabil Rehabil. 2001;23(14):635-38. [PMID:11697461] http://dx.doi.org/10.1080/09638280110038966

10. Orff HJ, Hays CC, Heldreth AA, Stein MB, Twamley EW. Clinical considerations in the evaluation and management of patients following traumatic brain injury. FOCUS J Lifelong Learn. 2013;11(3):328-40.

http://dx.doi.org/10.1176/appi.focus.11.3.328

11. van der Naalt J, van Zomeren AH, Sluiter WJ, Minderhoud JM. One year outcome in mild to moderate head injury: The predictive value of acute injury characteristics related to complaints and return to work. J Neurol Neurosurg Psychiatry. 1999;66(2):207-13. [PMID:10071101]

http://dx.doi.org/10.1136/jnnp.66.2.207

12. Belanger HG, Curtiss G, Demery JA, Lebowitz BK, Vanderploeg RD. Factors moderating neuropsychological outcomes following mild traumatic brain injury: A metaanalysis. J Int Neuropsychol Soc JINS. 2005;11(3):215-27. [PMID:15892898]

http://dx.doi.org/10.1017/S1355617705050277

13. Binder LM. Persisting symptoms after mild head injury: A review of the postconcussive syndrome. J Clin Exp Neuropsychol. 1986;8(4):323-46. [PMID:3091631]

http://dx.doi.org/10.1080/01688638608401325
14. Kinsella G, Murtagh D, Landry A, Homfray K, Hammond M, O’Beirne L, Dwyer L, Lamont M, Ponsford J. Everyday memory following traumatic brain injury. Brain Inj. 1996;10(7):499-507. [PMID:8806010]

http://dx.doi.org/10.1080/026990596124214

15. Vanderploeg RD, Crowell TA, Curtiss G. Verbal learning and memory deficits in traumatic brain injury: Encoding, consolidation, and retrieval. J Clin Exp Neuropsychol. 2001;23(2):185-95. [PMID:11309672] http://dx.doi.org/10.1076/jcen.23.2.185.1210

16. Vanderploeg RD, Curtiss G, Belanger HG. Long-term neuropsychological outcomes following mild traumatic brain injury. J Int Neuropsychol Soc JINS. 2005;11(3):228-36.

[PMID:15892899] http://dx.doi.org/10.1017/S1355617705050289

17. Belanger HG, Vanderploeg RD. The neuropsychological impact of sports-related concussion: A meta-analysis. J Int Neuropsychol Soc. 2005;11(4):345-57.

[PMID:16209414]

http://dx.doi.org/10.1017/S1355617705050411

18. Carroll LJ, Cassidy JD, Peloso PM, Borg J, von Holst H, Holm L, Paniak C, Pépin M; WHO Collaborating Centre Task Force on Mild Traumatic Brain Injury. Prognosis for mild traumatic brain injury: Results of the WHO Collaborating Centre Task Force on Mild Traumatic Brain Injury. J Rehabil Med. 2004; (43 Suppl):84-105.

[PMID:15083873]

http://dx.doi.org/10.1080/16501960410023859

19. Ruff R. Two decades of advances in understanding of mild traumatic brain injury. J Head Trauma Rehabil. 2005; 20(1):5-18. [PMID:15668567] http://dx.doi.org/10.1097/00001199-200501000-00003

20. Dawson DR, Schwartz ML, Winocur G, Stuss DT. Return to productivity following traumatic brain injury: Cognitive, psychological, physical, spiritual, and environmental correlates. Disabil Rehabil. 2007;29(4):301-13. [PMID:17364780] http://dx.doi.org/10.1080/09638280600756687

21. Wehman P, Targett P, West M, Kregel J. Productive work and employment for persons with traumatic brain injury: What have we learned after 20 years? J Head Trauma Rehabil. 2005;20(2):115-27. [PMID:15803036] http://dx.doi.org/10.1097/00001199-200503000-00001

22. Hoge CW, McGurk D, Thomas JL, Cox AL, Engel CC, Castro CA. Mild traumatic brain injury in U.S. Soldiers returning from Iraq. N Engl J Med. 2008;358(5):453-63. [PMID:18234750] http://dx.doi.org/10.1056/NEJMoa072972

23. Taylor BC, Hagel EM, Carlson KF, Cifu DX, Cutting A, Bidelspach DE, Sayer NA. Prevalence and costs of cooccurring traumatic brain injury with and without psychiatric disturbance and pain among Afghanistan and Iraq War Veteran V.A. users. Med Care. 2012;50(4):342-46. 


\section{[PMID:22228249]}

http://dx.doi.org/10.1097/MLR.0b013e318245a558

24. Seal KH, Bertenthal D, Miner CR, Sen S, Marmar C. Bringing the war back home: Mental health disorders among 103,788 US Veterans returning from Iraq and Afghanistan seen at Department of Veterans Affairs facilities. Arch Intern Med. 2007;167(5):476-82.

[PMID:17353495] http://dx.doi.org/10.1001/archinte.167.5.476

25. Pietrzak RH, Johnson DC, Goldstein MB, Malley JC, Southwick SM. Posttraumatic stress disorder mediates the relationship between mild traumatic brain injury and health and psychosocial functioning in veterans of Operations Enduring Freedom and Iraqi Freedom. J Nerv Ment Dis. 2009;197(10):748-53. [PMID:19829203] http://dx.doi.org/10.1097/NMD.0b013e3181b97a75

26. Vanderploeg RD, Belanger HG, Curtiss G. Mild traumatic brain injury and posttraumatic stress disorder and their associations with health symptoms. Arch Phys Med Rehabil. 2009;90(7):1084-93. [PMID:19577020]

http://dx.doi.org/10.1016/j.apmr.2009.01.023

27. Dijkers MP. Quality of life after traumatic brain injury: A review of research approaches and findings. Arch Phys Med Rehabil. 2004;85(4 Suppl 2):S21-35.

[PMID:15083419]

http://dx.doi.org/10.1016/j.apmr.2003.08.119

28. Findler M, Cantor J, Haddad L, Gordon W, Ashman T. The reliability and validity of the SF-36 health survey questionnaire for use with individuals with traumatic brain injury. Brain Inj. 2001;15(8):715-23. [PMID:11485611] http://dx.doi.org/10.1080/02699050010013941

29. Schiehser DM, Twamley EW, Liu L, Matevosyan A, Filoteo JV, Jak AJ, Orff HJ, Hanson KL, Sorg SF, DelanoWood L. The relationship between postconcussive symptoms and quality of life in veterans with mild to moderate traumatic brain injury. J Head Trauma Rehabil. 2015; 30(4):E21-8.

30. Emanuelson I, Andersson Holmkvist E, Björklund R, Stålhammar D. Quality of life and post-concussion symptoms in adults after mild traumatic brain injury: A populationbased study in western Sweden. Acta Neurol Scand. 2003; 108(5):332-38. [PMID:14616303]

http://dx.doi.org/10.1034/j.1600-0404.2003.00155.x

31. Morton MV, Wehman P. Psychosocial and emotional sequelae of individuals with traumatic brain injury: A literature review and recommendations. Brain Inj. 1995;9(1): 81-92. [PMID:7874099] http://dx.doi.org/10.3109/02699059509004574

32. Truelle J-L, Wild KV, Onillon M, Montreuil M. Social reintegration of traumatic brain-injured: The French experience. Asian J Neurosurg. 2010;5(1):24-31.

[PMID:22028740]
33. McLean AM, Jarus T, Hubley AM, Jongbloed L. Associations between social participation and subjective quality of life for adults with moderate to severe traumatic brain injury. Disabil Rehabil. 2014;36(17):1409-18.

[PMID:24059448]

34. Twamley EW, Thomas KR, Gregory AM, Jak AJ, Bondi MW, Delis DC, Lohr JB. CogSMART Compensatory cognitive training for traumatic brain injury: Effects over 1 year. J Head Trauma Rehabil. 2015;30(6):391-401.

[PMID:25033034]

http://dx.doi.org/10.1097/HTR000000000000076

35. Twamley EW, Jak AJ, Delis DC, Bondi MW, Lohr JB. Cognitive Symptom Management and Rehabilitation Therapy (CogSMART) for veterans with traumatic brain injury: Pilot randomized controlled trial. J Rehabil Res Dev. 2014; 51(1):59-70. [PMID:24805894]

36. Management of Concussion/mTBI Working Group. VA/ DoD clinical practice guideline for management of concussion/mild traumatic brain injury. J Rehabil Res Dev. 2009;46(6):CP1-68. [PMID:20108447]

37. Lehman AF. Measuring quality of life in a reformed health system. Health Aff (Millwood). 1995;14(3):90-101.

[PMID:7498907]

http://dx.doi.org/10.1377/hlthaff.14.3.90

38. Hamilton M. A rating scale for depression. J Neurol Neurosurg Psychiatry. 1960;23:56-62. [PMID:14399272] http://dx.doi.org/10.1136/jnnp.23.1.56

39. Blake DD, Weathers FW, Nagy LM, Kaloupek DG, Gusman FD, Charney DS, Keane TM. The development of a clinician-administered PTSD scale. J Trauma Stress. 1995; 8(1):75-90. [PMID:7712061] http://dx.doi.org/10.1002/jts.2490080106

40. Cicerone KD, Kalmar K. Persistent postconcussion syndrome: The structure of subjective complaints after mild traumatic brain injury. J Head Trauma Rehabil. 1995;10(3): 1-17. http://dx.doi.org/10.1097/00001199-199510030-00002

41. Delis DC, Kaplan E, Kramer JH, Ober B. California Verbal Learning Test-II. San Antonio (TX): Pearson Education, Inc; 2000.

42. Wechsler D. Wechsler Adult Intelligence Scale-Third Edition (WAIS-III). San Antonio (TX): PsychCorp; 1997.

43. Delis DC, Kaplan E, Kramer JH. Delis-Kaplan Executive Function System (D-KEFS). San Antonio (TX): Pearson Education, Inc; 2001.

44. Weathers FW, Ruscio AM, Keane TM. Psychometric properties of nine scoring rules for the Clinician-Administered Posttraumatic Stress Disorder Scale. Psychol Assess. 1999;11(2):124-33. http://dx.doi.org/10.1037/1040-3590.11.2.124

45. Gow AJ, Corley J, Starr JM, Deary IJ. Which social network or support factors are associated with cognitive abilities in old age? Gerontology. 2013;59(5):454-63. 
JRRD, Volume 53, Number 5, 2016

\section{[PMID:23711796]}

http://dx.doi.org/10.1159/000351265

46. Brown AW, Moessner AM, Mandrekar J, Diehl NN, Leibson CL, Malec JF. A survey of very-long-term outcomes after traumatic brain injury among members of a population-based incident cohort. J Neurotrauma. 2011;28(2): 167-76. [PMID:21121813] http://dx.doi.org/10.1089/neu.2010.1400

47. Dikmen SS, Corrigan JD, Levin HS, Machamer J, Stiers W, Weisskopf MG. Cognitive outcome following traumatic brain injury. J Head Trauma Rehabil. 2009;24(6):430-38. [PMID:19940676] http://dx.doi.org/10.1097/HTR.0b013e3181c133e9

48. Groswasser Z, Melamed S, Agranov E, Keren O. Return to work as an integrative outcome measure following traumatic brain injury. Neuropsychol Rehabil. 1999;9(3-4): 493-504. http://dx.doi.org/10.1080/096020199389545

49. Daggett V, Bakas T, Habermann B. A review of healthrelated quality of life in adult traumatic brain injury survivors in the context of combat veterans. J Neurosci Nurs. 2009;41(2):59-71. [PMID:19361122] http://dx.doi.org/10.1097/JNN.0b013e31819a7133
50. Trudel TM, Nidiffer FD, Barth JT. Community-integrated brain injury rehabilitation: Treatment models and challenges for civilian, military, and veteran populations. J Rehabil Res Dev. 2007;44(7):1007-16. [PMID:18075957] http://dx.doi.org/10.1682/JRRD.2006.12.0167

Submitted for publication November 26, 2014. Accepted in revised form October 2, 2015.

This article and any supplemental material should be cited as follows:

Orff HJ, Hays CC, Twamley EW. Multivariate assessment of subjective and objective measures of social and family satisfaction in Veterans with history of traumatic brain injury. J Rehabil Res Dev. 2016;53(5):541-50. http://dx.doi.org/10.1682/JRRD.2014.11.0295

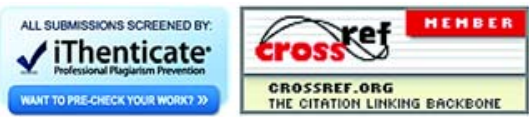

